\title{
Using a Monolingual Textual English Corpus in Translation
}

\author{
Samar Zeitoun \\ Centre of Language Sciences and Communication \\ Faculty of Literature and Humanities, Lebanese University \\ Beirut, Lebanon \\ Doha Dakik \\ Faculty of Arts \& Sciences \\ Lebanese International University, Beirut, Lebanon
}

\begin{abstract}
The purpose of this study is to examine the effects of using a monolingual English textual corpus on students' translations from Arabic into English with regards to the use of collocations and phrasal verbs. The research questions are: 1) How can the use of a monolingual corpus be introduced to translation students and incorporated into the translation process? 2) How does the use of a monolingual English textual corpus affect the quality of students' translations from Arabic into English regarding collocations and phrasal verbs? The research design used is an action research where an action plan was carried out with year 1 translation students and the instruments used are pre and posttests as well as formative assessment sheets. The group of students were introduced to corpora and their applications in translation, and taught how to use the online Corpus of Contemporary American English to solve translational problems of collocations and phrasal verbs. The analysis of results revealed the extent to which the use of such corpus helped students in improving the quality of their translations. The study highlighted the importance of adopting a corpus-based approach in the translation classroom and the benefits it offers as compared to the traditional approach.
\end{abstract}

Keywords: collocations, corpus-based approach, Corpus of Contemporary American English, phrasal verbs, traditional translation teaching

Cites as: Zeitoun, S., \& Dakik, D. (2018). Using a Monolingual Textual English Corpus in Translation. Arab World English Journal for Translation \& Literary Studies, 2 (4). 100-123. DOI: http://dx.doi.org/10.24093/awejtls/vol2no4.7 